http://doi.org/10.22352/AIP202149001

\title{
Editorial
}

\section{Zoobosque submarinos: una nueva aproximación morfofuncional para la ecología y conservación}

Nuestra percepción de que los animales son móviles mientras que las plantas viven fijas al suelo está muy arraigado en nuestro conocimiento colectivo. Tanto, así como que los bosques son estrictamente terrestres. Ambas percepciones se invierten drásticamente cuando se investigan las comunidades marinas. En donde - por ejemplo- las microalgas flotan libremente en el mar mientras que numerosas poblaciones de invertebrados son sésiles y pasan todo su ciclo vital adherido a un sustrato. Por lo que el término "zoobosques" (del inglés Animal Forest (Fig. 1)) se ha introducido para describir a aquellas comunidades de invertebrados sésiles, destacando las similitudes estructurales y funcionales con sus homólogas terrestres (Rossi et al., 2017).

Uno de los mejores ejemplos de zoobosques son los arrecifes de coral, debido a su gran biodiversidad, han sido definidos como las "selvas marinas". Sin embargo, durante las últimas décadas, muchos otros zoobosques han sido objeto de la atención de la comunidad científica. Por ejemplo, las comunidades de corales de aguas frías, que cumplen un papel clave en el funcionamiento de los ecosistemas y los potenciales sumideros de carbono en los ecosistemas bentónicos profundos. Del mismo modo, los avances tecnológicos han permitido explorar áreas por debajo de la zona fótica, revelando complejos y desconocidos zoobosques de aguas abisales. Por lo que los zoobosques son probablemente uno de los ecosistemas más ampliamente distribuidos en los océanos, desde los bancos de bivalvos en aguas someras hasta las comunidades de esponjas en las aguas antárticas (Cárdenas \& Montiel, 2017).

Sin embargo, en las últimas décadas se han ido acumulando pruebas de importantes cambios en los ecosistemas marinos debido a las perturbaciones provocadas por el hombre, que están reduciendo drásticamente la biodiversidad, la biomasa y la recuperación potencial de los zoobosques en todo el mundo. El concepto de zoobosque implica un enfoque holístico que permite conectar a diferentes ecosistemas bajo el mismo paraguas y que posiblemente conduzca a una mejor comprensión del ecosistema marino y a la aplicación de medidas eficaces de gestión y conservación.

\section{Dr. Américo Montiel San Martin}

Editor Jefe AIP 


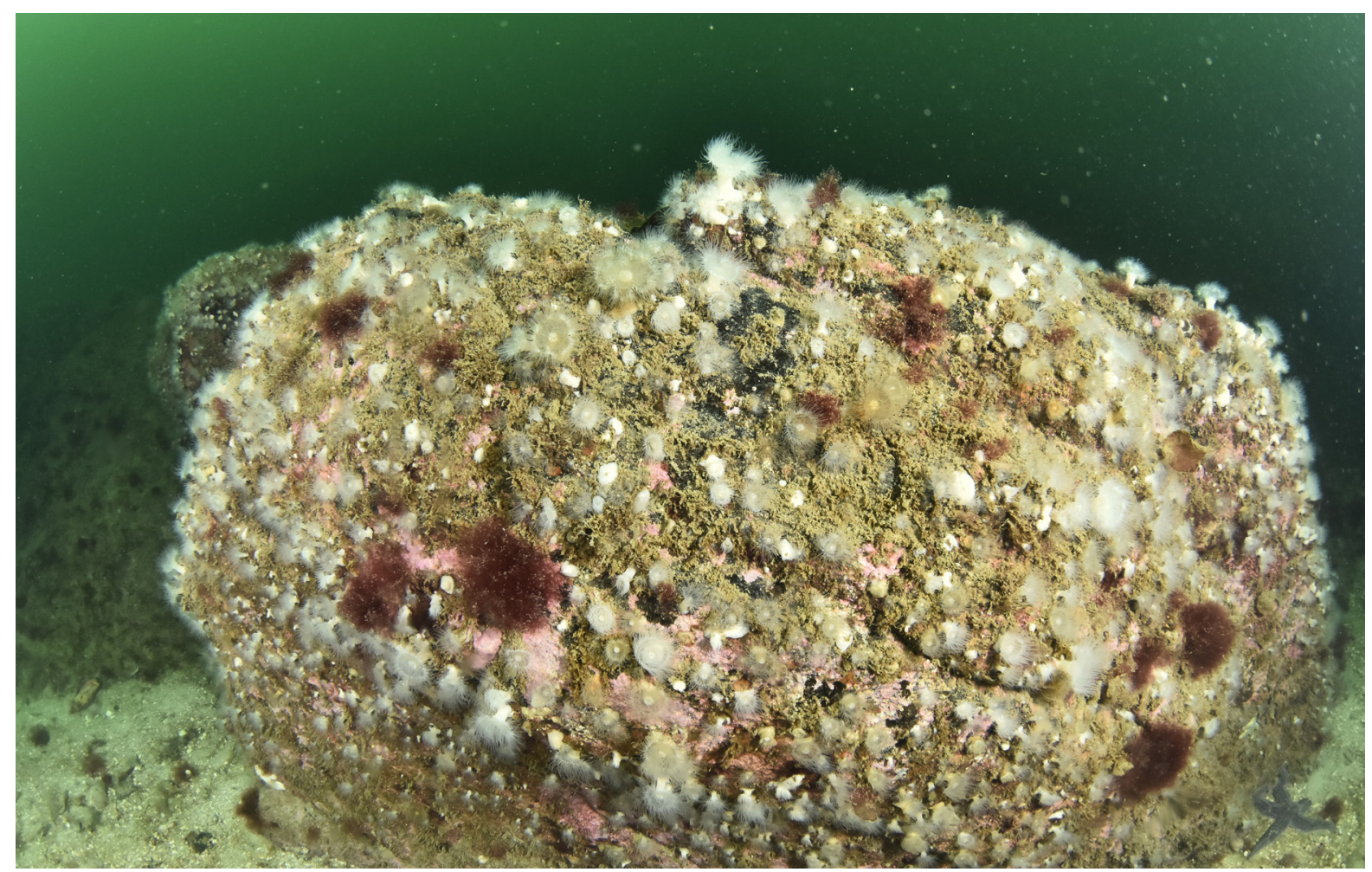

Fig. 1. Ejemplo de zoobosque regional que habita sobre una roca sumergida (Crédito Altamirano / Gorny OCEANA).

\section{LITERATURA CITADA}

Cárdenas, C. A., \& Montiel, A. (2017). Coexistence in cold waters: animal forests in seaweeddominated habitats in Southern high latitudes. Marine animal forests: the ecology of benthic biodiversity hotspots, 257-276.
Rossi, S., Bramanti, L., Gori, A., \& Orejas, C. (Eds.). (2017). Marine animal forests: the ecology of benthic biodiversity hotspots (pp. 1-1366). Cham: Springer International Publishing. 